\title{
Literature Review and Prospect of Enterprise Internal Control
}

\author{
Caihui Qin \\ School of Management, Jinan University, Guangzhou, China \\ Email: 17817716659@163.com
}

How to cite this paper: Qin, C.H. (2018) Literature Review and Prospect of Enterprise Internal Control. American Journal of Industrial and Business Management, $\mathbf{8}$, 2120-2132.

https://doi.org/10.4236/ajibm.2018.810140

Received: September 10, 2018

Accepted: October 20, 2018

Published: October 23, 2018

Copyright (c) 2018 by author and Scientific Research Publishing Inc. This work is licensed under the Creative Commons Attribution International License (CC BY 4.0).

http://creativecommons.org/licenses/by/4.0/

\begin{abstract}
This paper systematically reviews the literature related to internal control from 1973 to 2017, and reviews the internal control literature from two aspects at home and abroad. Based on this, the future research of China's internal control is prospected.
\end{abstract}

\section{Keywords}

Internal Control, Research Status, Prospect

\section{Introduction}

As a mechanism of great concern, internal control has attracted many scholars to study it, which has led the academic and practical circles to study the quality of internal control. Many scholars use a variety of different research methods to evaluate the internal control of enterprises.

\section{Foreign Related Research}

\subsection{Research on the Economic Consequences of Internal Control}

Doyle et al. (2007) and Ashbaugh-Skaife et al. (2008) found that the weaker the internal control of the company, the lower the accounting quality [1] [2] [3]. Hoitash et al. (2008) found that the severity and different nature of internal control deficiencies have different effects on audit fees. Kim et al. (2011) found that companies with significant internal control flaws and company-level internal control deficiencies have higher financing costs. Hoitash et al. (2012) found a significant negative correlation between major internal control deficiencies and CFO's salary changes, but this negative correlation was higher in companies with better corporate governance and companies with higher financial reporting misstatement costs and financial misstatement costs. High companies are more 
significant. Cheng et al. (2013) examined the investment behavior of companies that disclosed flaws in internal control under the SOX Act and found that these companies were prone to underinvestment or over-investment before they were disclosed. After the disclosure, the investment efficiency of these companies increased significantly [4]. Feng et al. (2015) used the shortcomings related to inventory management in financial reporting as a substitute for the major defects in the internal control of financial reporting, and studied its relationship with the company's operations. The study found that the internal control of financial reporting has significant operational efficiency for the company influences [5]. Huang et al. (2015) found that companies that disclose significant internal control defects have more cash holdings than non-disclosed companies [6]. Cheng et al. (2017) found that the company's internal control has major flaws that will seriously reduce its operational efficiency [7]. Correcting major defects can improve operational efficiency. This negative impact is more obvious for companies that need a lot of information to make decisions and smaller companies. Caplan et al. (2017) used the internal control major flaws of Section 404 of the SOX Act as a proxy variable for the quality of corporate financial reporting, using future goodwill impairments to represent the quality of managerial $M \& A$ decisions, and studying the quality of financial reporting on corporate $M \& A$ decisions. The impact of quality, the study found that the disclosure and correction of internal control defects will further improve the quality of the company's M \& A decisions.

\subsection{Factors Affecting the Quality of Internal Control}

Lin et al. (2001) found that internal audits of enterprises help to reduce major flaws in internal control. Krishnan (2005) found that the more independent and professional the audit committee of the company, the less internal control problems the company has. Doyle et al. (2007) conducted a more comprehensive study on the factors affecting the quality of internal control. He found that the level of internal control of the company is closely related to factors such as the size of the company, the length of the listing, the financial status, and the complexity of the business operations. Bardhan et al. (2015) studied the relationship between the characteristics of family business and non-family business and the quality of internal control of financial reporting [8]. It was found that the internal control of financial reporting of family enterprises has more significant defects than that of non-family enterprises, that is, the owners of family enterprises have Motivation for low-quality internal control construction for personal gain. Lee (2016) investigated the relationship between overconfidence, CEO's cognitive bias and internal control deficiencies [9]. The empirical results show that CEO's overconfidence is positively correlated with internal control deficiencies, which leads to a decline in earnings quality. In addition, CEO's overconfidence on financial reporting the potential negative impact of internal control effectiveness reduces investor trust in financial reporting. Anantharaman et al. (2016) explored how the review process of regulators (especially the Securities and Ex- 
change Commission SEC) affected the disclosure of internal control deficiencies [10]. The results of the study indicate that the SEC committee's review helps to improve the effectiveness of internal control reports. The study will help to further understand the decisive factors in registering company internal control reports. Kharraz et al. (2017) used logistic regression model studies to find that internal control deficiencies were not significantly related to corporate governance and ownership structure, but were significantly related to other corporate characteristics (eg, company size), thereby facilitating auditors to reveal the Tunisian stock exchange [11]. Determinants of defects in the internal control system of listed companies. In summary, the factors considered to affect internal control in foreign studies are shown in Table 1.

\subsection{Research on Internal Control Evaluation}

Based on the subjective judgment of the evaluator and the internal control evaluation of the pure mathematical model. Early internal control studies have shown that personal judgment and professional experience have a significant impact on internal control evaluation, so the evaluation of internal control is mostly based on this (Robert, 1974; Robert and Kramer, 1980; Robert and Kramer, 1980; Hamilton and Wright, 1982), the evaluation results are more subjective because there are no clear evaluation methods or systems available. In order to avoid the excessive subjectivity of internal control evaluation, many scholars have proposed different improvement methods. Yu and Neter (1973) established a stochastic model that allows auditors to objectively evaluate the reliability of internal control systems in quantitative terms. Robert and William (1982) added new indicators such as stability and related weights to reduce subjectivity, and combined with the relationship between auditors' practice experience and personal judgment to achieve the objective of improving the internal control evaluation method or system. Donald (1983) used a working paper obtained from an office performing an audit task in conjunction with discriminant analysis (i.e., multivariate statistical analysis) to construct a descriptive internal control basic evaluation. Richard. H. Tabor (1983) selected 109 listed companies audited by the "Big Four" accounting firms as research samples, using the evidence collected during the research process and the data provided by the "Big Four" accounting firms. Study the correlation between the internal control evaluation of listed companies and the sample size of substantive procedures. John and James (1983) propose a fuzzy set model that summarizes internal control judgments. Srivastav (1985) constructs a theoretical model for evaluating internal control, and proposes three criteria for the effectiveness of internal control: the probability that the control program (procedure) is executed, the probability of making correct decisions on the correct input information, and the input error information, the probability of making the right decision. Johnson et al. (1986) studied computer control as a primary method for internal control evaluation. Rayman et al. (1986) constructed a computational model examining the internal control 
Table 1. Influencing factors of internal control quality.

\begin{tabular}{cc}
\hline Influencing factor & Research scholar \\
\hline Internal Audit & Lin et al. (2001) and Krishnan (2005) \\
$\begin{array}{c}\text { Factors such as company size, } \\
\text { length of listing, financial status, } \\
\text { complexity of business operations, etc. } \\
\text { Family factor }\end{array}$ & Doyle et al. (2007), Kharraz et al. (2017) \\
Overconfidence, CEO's cognitive bias & Bardhan et al. (2015) \\
External Audit & Lee (2016) \\
\hline
\end{tabular}

process to evaluate internal controls. Purivs (1989) proposed three methods for evaluating internal control: text narrative, questionnaire, and flow chart. Mahamad (1993) proposed a model to describe the structure and evaluate internal controls. Bierstaker et al. (2002) used empirical research methods to examine auditors' internal control evaluation behaviors and found that they used questionnaires more effectively than textual descriptions when identifying internal control design flaws.

The internal control model proposed by the above scholars does not need to rely too much on the subjective judgment of the evaluator, or is too purely physics and physics, resulting in the lack of practical proxy variables in the actual application, the model hypothesis is difficult to accept and the cost of use is relatively high. In advanced situations, they are not widely adopted in practice. However, it laid the foundation for the follow-up researchers to continue to study and construct a scientific and reasonable internal control evaluation system.

In the United States, the COSO Committee released the landmark "Internal Control-Integration Framework" in 1992. After several years of establishing an internal control framework to evaluate and evaluate the internal control status of enterprises, it has become a new research hotspot. It integrates the various concepts and interpretations of internal control that exist in reality, and provides a reference standard for enterprises to evaluate the effectiveness of their internal control systems. After the Enron incident in 2002, in order to restore the confidence of US investors in the capital market, the US Congress and the government accelerated the adoption of the Sarbanes-Oxley Act (SOX Act). After the release of the Internal Control-Integration Framework, foreign scholars have evaluated internal control from the following aspects: one is based on the major defects published by the accounting firm as the basis for evaluation; the other is the internal control information that the enterprise voluntarily discloses. The evaluation basis; the third is the basis of internal control as the evaluation basis; the fourth is based on the five elements of internal control.

1) Based on the major defects published by the accounting firm as the basis for evaluation. SOX Acts 302 and 404 require listed companies not only to disclose internal control reports in their periodic reports, but also to self-evaluate the effectiveness of internal controls, and external auditors must also provide 
internal control visa reports, i.e., the company must disclose the substance. Major flaws in the internal control of sexual content. Li Xiang (2009) believes that the flaw in internal control is a sign that the internal control of the company (financial report) is ineffective and risky, and it is regarded as a senior manager's dereliction of duty in internal control. Some scholars have done a lot of empirical research on the influencing factors and economic consequences of internal control defects and found that the size of the company, the time of its establishment, the complexity of its operating status, the recent changes in organizational structure, the disclosed accounting risks, profitability, In addition to corporate internal factors such as corporate governance, investor protection, different systems, and different cultures can have a significant impact on corporate internal controls (Ashbaugh-Skaife et al., 2007, 2008; Loeone, 2007; Doyle et al., 2007a, 2007b; Zhang, 2007; Engel et al., 2007; Leuz et al., 2007, 2008; Naicer and Sharma, 2009; Li et al., 2010; Costello and Wittenberg-Moerman, 2011, etc.). Ashbaugh, Collins and Kinney (ACK), Doyle, Ge, and McVay (DGM) provided evidence of the first factors related to internal control deficiencies (ICDs) that led to company disclosure under SOX Acts 302 and 404, Leone (2007) After summarizing the research, it lists the indicators that may lead to internal control deficiencies and believes that these studies will lay the foundation for future research on internal control deficiencies (ICDs).

2) The internal control information that the company voluntarily disclosed is used as the evaluation basis. Botosan (1997) based on the information disclosed by 122 manufacturing companies on a voluntary basis, combined with the company report ranking of The Association for Investment Management and Research (AIMR), constructed the company's Disclosure Level Index (DSCORE) and empirically examined the company's disclosures. The impact of the level on the cost of equity capital of the company is the earliest study to use the quantitative means to construct the company's disclosure level. Many scholars have extended the research on the internal control disclosure index.

3) The objective of internal control is used as the basis for evaluation. Based on COSO's Enterprise Risk Management-Integration Framework, Chil-Yang Tseng (2007) built a risk management index based on strategic, operational, reporting, and compliance objectives [12]. The index uses four targets as the primary indicators. Under each of the primary indicators, there are two secondary indicators to measure their achievement. Adding these eight secondary indicators is equal to the enterprise risk management index. This is international. The literature on the use of this method is to develop an index earlier (Chinese listed company internal control index research group, 2010). Jokilii (2009) conducted a questionnaire survey on the effectiveness of 744 Finnish companies' internal controls. He defined the effectiveness of internal control as the management's understanding of the degree of internal control objectives, and the internal control of the target's degree of achievement.

4) Based on the five elements of internal control. EI Paso (2002) constructed 
the internal control evaluation model from the five elements of the COSO report, which consists of two levels. The first level is the five elements of internal control, the second level is the specific indicator for measuring the five elements, and the control environment is 43.12 evaluations, 10 control activities, 14 information communication, and 14 monitoring activities formed a questionnaire containing 93 specific indicators, and self-evaluated internal control through questionnaire survey of company employees. Lembi Noorvee (2006) established four first-level indicators based on the COSO Report (1992), namely control environment, risk assessment, information and communication and monitoring, and second-level indicators under the first-level indicators, including 7 control environments. 3 risk assessments, 5 information and communication, 3 monitoring activities, and a total of 18 secondary indicators. Based on the five elements of COSO (1992), Schwartz (2006) designed an internal control evaluation model based on business process integration for small listed companies. There are five steps, and each step has a corresponding evaluation template. The internal control can be evaluated according to its own situation and the evaluation template. Chen et al. (2017) developed an internal control index based on the internal control index to evaluate the internal control of Chinese listed companies, and used AHP to quantify the internal control of listed companies and verified the relationship between internal control quality and earnings management. The relationship validates the validity of the index and finds that the higher the quality of internal control, the higher the credibility of the company's financial reporting.

In summary, in recent years, there have been relatively few studies on the internal control of SMEs in foreign countries. The existing research on the influencing factors of internal control, economic consequences and internal control evaluation provides reference for the follow-up researchers to conduct internal control construction and internal control evaluation.

\section{Domestic Related Research}

China's regulatory authorities have drawn on the experience of the United States to introduce a series of policy norms on internal control. In 2006, the "Guidelines for Internal Control of Listed Companies" issued by the Shanghai and Shenzhen Stock Exchanges and the "Basic Standards for Internal Control of Enterprises" issued by the Ministry of Finance and other ministries in June 2008 required listed companies to disclose internal control self-evaluation and hire intermediaries. The accounting firm conducts an evaluation review. The introduction of these policy norms has made academic and practical circles increasingly concerned about internal control.

\subsection{Research on the Economic Consequences of Internal Control Quality}

Li Wanfu et al. (2011) examined the role of internal control in corporate invest- 
ment and found that lower internal control quality exacerbates the company's inefficient investment, including over-investment and under-investment [13]. Lu Rui et al. (2011) examined the impact of internal control on the sensitivity of executive compensation performance. The higher the internal quality, the higher the sensitivity of management compensation [14]. Chen Hanwen and Zhou Zhongsheng (2014) found that the better the internal control quality of the enterprise, the lower the bank debt cost obtained; in addition, they also found that the impact of internal control quality on corporate bank debt financing costs in non-state-owned holding companies and financial markets Industries that are more competitive in developed regions and product markets are more prominent [15]. Zhang Chuancai et al. (2017) used the "China Internal Control Index of Listed Companies" constructed by Chen et al. (2016) to measure the quality of internal control of enterprises and study the impact of product competition on the quality of internal control under different property rights. The study found that the market competition of products is more intense. The higher the internal control quality of the enterprise, and the discovery of high quality internal control quality can further enhance the market competitive advantage of the product [16] [17]. Ao Xiaobo et al. (2017) used the credit rating of bond market bonds as an entry point to analyze the impact of internal control on bond credit rating. The study found that the higher the quality of internal control, the higher the bond credit rating or subject credit rating. The corresponding financing costs are lower [18].

\subsection{Research on the Influencing Factors of Internal Control}

Zhang Ying and Zheng Hongtao (2010) found that the more effective internal audits, the lower the probability of corporate irregularities [19]. Liu Qiliang et al. (2012) found that the quality of internal control of local government-controlled companies is relatively poor; in addition, the higher the degree of marketization in the region where the company is located, the better the internal control quality [20]. Zhang Jide et al. (2013) found that management's attention is the most critical factor affecting the effectiveness of internal control. Chi Guohua et al. (2014) started from the characteristics of executive background, and found that the influence of different executive background characteristics on internal control quality is quite different. Liu Yunguo et al. (2016) examined the impact of the participation level of non-state-owned shareholders on the internal control of state-owned enterprises. It was found that the participation of non-state-owned shareholders in the high-level governance dimension is conducive to improving the quality of internal control of state-owned enterprises, and this effect only exists in competitive state-owned enterprises and Local state-owned enterprises. Cheng Bo et al. (2016) put Confucianism in Chinese traditional culture into the framework of internal control analysis [21]. It is found that Confucian culture can improve the information environment and strengthen contract performance to a certain extent, and im- 
prove the quality of internal control. The role is higher in high companies. Xiang Rui et al. (2017) used the internal control index of China's listed companies constructed by the Xiamen University Internal Control Task Force to empirically test the relationship between the background characteristics of the audit committee director and the internal control quality of the company. The study found that the audit committee director's education level, salary level, reputation Both localization and localization can have a positive impact on the quality of internal control of listed companies, and can affect the five elements of internal control to varying degrees [22]. In summary, the factors that can be considered to affect internal control in foreign studies are shown in Table 2.

\subsection{Research Related to Internal Control Evaluation}

1) Research on the index system of general internal control evaluation system

Summarizing the research ideas of domestic scholars, the methods of constructing the internal control evaluation index mainly include the combination of "element view", "object view", "factor view" and "object view”, "elemental view." Wang Yuyu and Wen Tao (2005) constructed an internal control evaluation index system consisting of 35 specific indicators from five aspects: internal control environment, risk assessment, internal accounting control, internal management control and supervision and control [23]. Shenzhen Dibo Risk Management Technology Co., Ltd. (2009) regards the five elements of internal control as the first-level indicator, and sets 26 secondary indicators and 63 third-level indicators to evaluate internal control, using ranking analysis and mean comparison method. , regression analysis, and correlation analysis analyze the internal control of listed companies [24]. Chen Hanwen (2010) constructed the internal control evaluation index of listed companies with the five elements of internal control of COSO Report (1992) as the logical framework [25]. Li Yingqi et al. (2013) consist of five primary indicators, including internal environment, risk assessment, control activities, information and communication, and internal supervision, according to the Ministry of Finance's reference indicators. There are 18 secondary indicators and 57 third-level indicators under the first-level indicators. 45 kinds of four-level indicators, a total of 84 detailed indicators constitute internal control evaluation indicators for the first time in China to implement the listed company's internal control evaluation mandatory disclosure of information disclosure status, the study found that the sample company's overall internal control evaluation information in 2011 [26]. The disclosure level is not high, the Shanghai company has a higher degree of compliance with the new norms than the deep market, and the differences in the internal control evaluation information disclosure of companies with different characteristics are significant. The evaluation of internal control around the five elements of internal control ignores the internal control of the enterprise as an artificial system. The effectiveness of its constituent elements is not completely consistent with the effectiveness of the overall operation of the system and the effectiveness 
Table 2. Influencing factors of internal control quality.

\begin{tabular}{cc}
\hline Influencing factor & Research scholar \\
\hline Internal Audit & Zhang Ying and ZhengHongtao (2010), \\
Xiang Rui et al. (2017) \\
Nature of business \\
Management's emphasis \\
culture & Liu Qiliang et al. (2012), Liu Yunguo, etc. (2016) \\
Zhang Jide et al. (2013), Chi Guohua, etc. (2014) \\
Cheng Bo et al. (2016)
\end{tabular}

of the overall operation of the system. Relationships, and this method also needs to rely on the experience of the reviewers to make the evaluation conclusions lack of objectivity (Zhang Zhaoguo et al., 2011) [27].

2) "Target view." Li Yuhong (2011) built an internal control index based on strategic goals, business objectives, financial reporting reliability goals and compliance objectives, but the index did not take asset security into account, and the article did not combine qualitative and quantitative, so it was constructed. The internal control index does not fully reflect the level of internal control of the firm [28]. Zhang Xianzhi and Dai Wentao (2011) built the theoretical framework and evaluation model of the comprehensive evaluation system of internal and external supervision of the Trinity (enterprise, CPA and relevant regulatory authorities) based on the realization of the goal of internal control [29]. Zhang Zhaoguo et al. (2011) built an internal control evaluation index system based on the realization degree of internal control objectives, and constructed 25 specific indicators to evaluate internal control from the five perspectives of strategy, operation, reporting, compliance and asset security. The empirical test shows that the evaluation index system has high effectiveness. The Research Group on Internal Control Index of China's Listed Companies (2011) uses the basic framework system of internal control of enterprises as the system basis, and designs the basic index of internal control based on the five objectives of internal control and conducts an empirical test. This study is to evaluate each internal control. After the specific indicators are standardized, the arithmetic average is used to calculate the weight to calculate the internal control index of the listed company, so the index is more objective, comparable and operability [30]. Lin Bin et al. (2014) based on China's institutional background, divided the five objectives of internal control into three levels: foundation, management, and strategy. Under these three levels, select specific indicators corresponding to them, and at the same time, internal control important defects. And the major defects were used as correction indicators to construct an internal control index, but the study did not empirically test the internal control index [31].

3) "Target view" combined with "factor view". Han Chuanmo and Wang Shiguo (2009) constructed an internal control evaluation index system from three dimensions. The first dimension is the goal dimension, that is, realizing the enterprise development strategy, improving operational efficiency and effectiveness (including asset security), financial report and related information. The 
four objectives of legal compliance of business management; the second dimension is the control element dimension, including internal environment, risk assessment, control activities, information communication and internal supervision; the third dimension is organizational dimension, including subsidiary layer, The business unit level, the branch level and the company's overall level are four levels, and then the various control measures are scored by the fuzzy evaluation method, and finally the overall score of the internal control of the enterprise is determined [32]. Li Lianhua and Tang Guoping (2012) designed a system that fits the theoretical framework by combining the five elements of internal control in accordance with the design efficiency and execution efficiency through the combination of transfer effects and internal control objectives [33]. Chi Guohua and Guo Jingjing (2015) believe that the existing methods of internal control mainly include three types of "defect view", "factor view" and "target view". These three methods have their own advantages and disadvantages. Therefore, they From the perspective of "view", based on COSO "Internal Control - Integration Framework", China's "Basic Standards for Internal Control of Enterprises" and its supporting guidelines, the five elements of internal control are used as the logical framework to absorb the "defect view" and "target" The advantage of "view" is to construct a set of internal control quality evaluation index system with operability and scientificity [34].

In summary, similar to the research situation in foreign countries, in recent years, there have been many studies on the internal control of listed companies in China, and there are relatively few studies on the internal control of SMEs. Researches on internal control factors, economic consequences and internal control evaluations at home and abroad have provided reference for domestic follow-up researchers to conduct internal control construction and internal control evaluation.

\section{Conclusions}

From the above literature review at home and abroad, it can be seen that domestic and foreign scholars' research on internal control is mostly based on listed companies, while listed companies are generally large and medium-sized enterprises. Research on internal control of small enterprises is rare less. The proportion of small enterprises in enterprises is a major driving force for China's economic growth. However, today, there are the following problems in the internal control construction of small enterprises in China: the managers of small enterprises fail to correctly recognize the importance of internal control; the internal control system is imperfect; the integration of personnel is responsible for implementing and supervising internal control construction. The quality is not high. The existence of these problems makes it difficult for internal control to function properly. High-quality internal control helps to improve the management and risk prevention capabilities of small businesses and promote their healthy and sustainable development. In order to improve the internal control 
level of small enterprises, this paper believes that the following points should be achieved: managers should correctly recognize the importance of internal control; improve the internal control system based on the five elements of COSO's internal control; the scientific and reasonable internal control evaluation system supervises the internal control of small enterprises. Therefore, in the future research of internal control in China, the research on the internal control construction of small enterprises and the internal control evaluation of small enterprises is a research field with practical value and theoretical value.

The research contribution of this paper is to sort out the related research of internal control, and provide the follow-up researchers with the fields that need further research in internal control.

The shortcoming of this paper is that it does not analyze in detail which factors will affect the development of internal control construction of small enterprises, and the factors that should be considered when conducting internal control evaluation of small enterprises. This needs to be further improved and expanded in the future.

\section{Conflicts of Interest}

The author declares no conflicts of interest regarding the publication of this paper.

\section{References}

[1] Doyle, J., Ge, W. and McVay, S. (2007) Determinants of Weaknesses in Internal Control over Financial Reporting. Journal of Accounting and Economics, 44, 193-223. https://doi.org/10.1016/j.jacceco.2006.10.003

[2] Ashbaugh-Skaife, H., Collins, D.W. and Kinney, W. (2007) The Discovery and Reporting of Internal Control Deficiencies Prior to SOX-Mandated Audits. Journal of Accounting and Economics, 44, 166-192. https://doi.org/10.1016/j.jacceco.2006.10.001

[3] Ashbaugh-Skaife, H., Collins, D.W. and Kinney, W. (2008) The Effect of SOX Internal Control Deficiencies and Their Remediation on Accrual Quality. The Accounting Review, 83, 217-250. https://doi.org/10.2308/accr.2008.83.1.217

[4] Cheng, M., Dhaliwal, D. and Zhang, Y. (2013) Does Investment Efficiency Improve after the Disclosure of Material Weaknesses in Internal Control over Financial Reporting? Journal of Accounting and Economics, 56, 1-18. https://doi.org/10.1016/j.jacceco.2013.03.001

[5] Feng, M., Li, C., McVay, S. and Skaife, H. (2015) Does Internal Control over Financial Reporting Affect a Firm's Operations? Evidence from Firm's Inventory Management. The Accounting Review, 90, 529-557. https://doi.org/10.2308/accr-50909

[6] Huang, P., Guo, J., Ma, T. and Zhang, Y. (2015) Does the Value of Cash Holdings Deteriorate or Improve with Material Weaknesses in Internal Control over Financial Reporting? Journal of Banking \& Finance, 54, 30-45. https://doi.org/10.1016/j.jbankfin.2015.01.007

[7] Cheng, Q., Goh, B.W. and Kim, J.B. (2017) Internal Control and Operational Efficiency. Research Collection School of Accountancy, 1, 1-47.

[8] Bardhan, I., Lin, S. and Wu, S. (2015) The Quality of Internal Control over Finan- 
cial Reporting in Family Firms. Accounting Horizons, 29, 41-60. https://doi.org/10.2308/acch-50935

[9] Lee, J.E. (2016) CEO Overconfidence and the Effectiveness of Internal Control over Financial Reporting. The Journal of Applied Business Research, 32, 81-100. https://doi.org/10.19030/jabr.v32i1.9525

[10] Anantharaman, D. and He, L. (2016) Regulatory Scrutiny and Reporting of Internal Control Deficiencies: Evidence from the SEC Comment Letters. SSNR, 1, 1-44.

[11] Kharraz, H. and Ferchichi, J. (2017) Determinants of Voluntary Disclosure of Internal Control Weaknesses in Tunisia. Corporate Ownership \& Control, 14, 59-69. https://doi.org/10.22495/cocv14i2art6

[12] Tseng, C.Y. (2007) Internal Control, Enterprise Risk Management, and Firm Performance. Simth School of Business.

[13] Li, W.F., Lin, B. and Song, W. (2011) The Role of Internal Control in Corporate Investment: Efficiency Promotion or Suppression? Management World, 2, 81-99.

[14] Lu, R., Liu, J.H. and Xu, N. (2011) Internal Control, Property Rights and Executive Compensation Performance Sensitivity. Accounting Research, No. 10, 42-48.

[15] Chen, H.W. and Zhou, Z.S. (2014) Internal Control Quality and Corporate Debt Financing Costs. Nankai Management Review, 3, 103-111.

[16] Zhang, C. and Chen, H. (2017) Product Market Competition, Property Rights and Internal Control Quality. Accounting Research, 5, 67-75.

[17] Chen, H., Wang, D. and Zhou, N. (2017) A Comprehensive and Quantitative Internal Control Index: Construction, Validation, and Impact. Review of Quantitative Finance and Accounting, 49, 337-377. https://doi.org/10.1007/s11156-016-0593-x

[18] Ao, X., Lin, W. and Li, X. (2017) Internal Control Quality and Bond Credit Rating. Audit Research, No. 7, 57-64.

[19] Zhang, Y. and Zheng, H. (2010) Investigation and Analysis of the Effectiveness of Internal Control in China's Enterprises and Its Influencing Factors. Audit Research, No. 1, 75-81.

[20] Liu, Y., Zheng, Q. and Cai, G. (2016) Does Non-State-Owned shareholders Improve the Quality of Internal Control of State-Owned Enterprises?-Evidence from State-Owned Listed Companies! Accounting Research, No. 4, 61-68.

[21] Cheng, B., Pan, F. and Wang, J. (2016) Confucian Culture, Information Environment and Internal Control. Accounting Research, No. 12, 79-84.

[22] Xiang, R., Xu, Y. and Yang, Y. (2017) Background Characteristics of the Director of the Audit Committee and the Quality of Internal Control of the Company. Audit Research, 4, 73-80.

[23] Wang, Y. and Wen, T. (2005) Evaluation Model and Application of Enterprise Internal Control. Statistics \& Decision, No. 2, 131-132.

[24] Shenzhen Dibo Enterprise Risk Enterprise Management Technology Co. Ltd. (2009) Abstract of White Paper on Internal Control of Chinese Listed Companies in 2009. China Securities Journal, 2009-7-16, B08.

[25] Xiamen University Internal Control Index Research Group, Internal Control Index of Chinese Listed Companies (2009) Formulation, Analysis and Evaluation. China Securities Journal, 2010-6-11, A21.

[26] Li, Y., Chen, C. and Yu, J. (2013) Information Disclosure of Internal Control Evaluation of Listed Companies in China: Problems and Improvements-Evidence from 
2011 Internal Control Evaluation Reports. Accounting Research, No. 8, 62-68.

[27] Zhang, Z., Zhang, W. and Yang, Q. (2011) Construction and Empirical Test of Internal Control Evaluation System under Target Guidance. Nankai Business Review, No. 7, 148-156.

[28] Li, Y. (2011) Corporate Governance Structure and Internal Control Effectiveness-An Empirical Study Based on Listed Companies in Shanghai Stock Exchange. Chinese Certified Public Accountant, No. 3, 69-75.

[29] Zhang, X. and Dai, W. (2011) Research on Internal Control Evaluation System of Chinese Enterprises. Audit Research, No. 1, 69-78.

[30] Research Group on Internal Control Index of Chinese Listed Companies (2011) Research on Internal Control Index of Chinese Listed Companies. Accounting Research, No. 12, 20-24.

[31] Lin, B., Lin, D., Hu, W., Xie, F. and Yang, W. (2014) Research on Goal-Oriented Internal Control Index. Accounting Research, No. 8, 16-24.

[32] Han, C. and Wang, S. (2009) Fuzzy Comprehensive Evaluation of Enterprise Internal Control Based on AHP. Accounting Research, No. 4, 55-61.

[33] Li, L. and Tang, G. (2012) Internal Control Efficiency: Theoretical Framework and Measurement Evaluation. Accounting Research, No. 5, 16-25.

[34] Chi, G. and Guo, J. (2015) Research on Internal Control Index of Listed Companies Based on the Perspective of "Integration View". Research on Financial and Economic Issues, No. 8, 75-82. 